\title{
Nutritional quality and staling of wheat bread partially replaced with Peruvian mesquite (Prosopis pallida) flour
}

\author{
Ursula Gonzales-Barron $^{\mathrm{a}, *}$, Rody Dijkshoorn ${ }^{\mathrm{a}, \mathrm{b}}$, Maikel Maloncy ${ }^{\mathrm{b}}$, Tiane Finimundy ${ }^{\mathrm{a}}$, \\ Marcio Carocho ${ }^{a}$, Isabel C.F.R. Ferreira ${ }^{a}$, Lillian Barros ${ }^{a}$, Vasco Cadavez ${ }^{a}$ \\ ${ }^{a}$ Centro de Investigação de Montanha (CIMO), Instituto Politécnico de Bragança, Campus de Santa Apolónia, 5300-253 Bragança, Portugal \\ ${ }^{\mathrm{b}}$ The Hague University of Applied Sciences, Johanna Westerdijkplein 75, room Oval 1.01, 2521 EH The Hague, the Netherlands
}

\section{A R T I C L E I N F O}

\section{Keywords:}

Algarroba

Composite bread

Fatty acids

Texture profile analysis

Shelf life

\begin{abstract}
A B S T R A C T
The objective of this study was to evaluate the effect of partially replacing two types of wheat flour (low ash content [type 55] and high ash content [type 65]) with Peruvian Prosopis pallida (mesquite) pod flour (0, 5, 10, $15 \%$ ) on the nutritional quality and staling of composite breads. Mesquite flour (MF) enhanced the nutritional quality by increasing the fibre contents and unsaturated fatty acids of the bread. MF did not affect crumb hardness either when prepared with wheat flour type $65(\mathrm{p}=0.374)$ or $55(\mathrm{p}=0.122)$, but reduced crumb resilience $(\mathrm{p}<0.001)$ and water activity $(\mathrm{p}=0.003)$ in both wheat flour types. When blended with wheat flour type 55, increasing levels of MF delayed the dehydration $(\mathrm{p}<0.001)$ and resilience loss rates. Likewise, the higher the MF level, the slower the crumb hardening of composite breads formulated with wheat flour type 55 $(\mathrm{p}=0.028)$. Thus, MF did not only enhance the nutritional profile of composite breads, but could also retard staling as a supplement of wheat flour type 55.
\end{abstract}

\section{Introduction}

Prosopis genus belongs to the leguminous (Fabaceae) family. There are 44 species, three of them are native to Asia, one to Africa, and all the rest to America (Sciammaro, Ferrero, \& Puppo, 2016). These are nitrogen-fixing trees that present drought and heat tolerance, and thus are able to grow in more severe environmental conditions than common annual legumes (Felker, Grados, Cruz, \& Prokopiuk, 2003). Prosopis pods are sweet fruits formed of 70-75\% pericarp (epicarp, mesocarp, and endocarp) and 25-30\% seeds (episperm, endosperm and cotyledons) (Sciammaro et al., 2016). These pods contain a high amount of carbohydrates, mainly fibre and soluble sugars, and a moderate quantity of proteins; and have been also found to be a source of bioactive compounds with antioxidant, anti-inflammatory and antihypertensive activities (Díaz-Batalla, Hernández-Uribe, Román-Gutiérrez, CariñoCortés, Castro-Rosas \& Téllez-Jurado, 2018). Whole ripe pods of Prosopis spp. are ground to produce flour, known as "mesquite flour" in the US and "algarroba flour" in South America. Mesquite or algarroba flour is brown, sweet, and has a distinctive aroma that resembles coffee, cocoa, molasses and hazelnut (Felker et al., 2003). Due to its amino acidic profile, which is nutritionally complementary with cereal proteins (Marangoni \& Alli, 1988), and its high content of fibre, potassium, calcium and iron (Sciammaro et al., 2016), mesquite flour has a good potential to be used in healthy cereal based formulations such as composite breads.

Thus, mesquite flour from Prosopis alba Griseb. native to Argentina, has been studied as a wheat flour replacer in breadmaking. Bigne, Puppo, and Ferrero (2016a,b) investigated the effects of different levels of mesquite flour on the nutritional and technological qualities of white wheat bread; and later on the improvement of the textural properties by addition of transglutaminase (Bigne, Romero, Ferrero, Puppo, \& Guerrero, 2017). Mesquite flour from Prosopis alba has also been tested as a functional ingredient in a series of sweet baked products (Correa et al., 2017), including panettone-like bread (Bigne, Puppo, \& Ferrero, 2018). They demonstrated that replacement with mesquite flour diminished crumb resilience and increased adhesiveness. Furthermore, part-baking technology was enhanced since frozen bread produced with mesquite flour retained the textural parameters of non-frozen bread after eight-week storage at $-18^{\circ} \mathrm{C}$.

Prosopis pallida (Humb. \& Bonpl. Ex. Willd-) Kunth, a native species of the semiarid coastal region of Peru, produces pods of very different composition from those of Prosopis alba. Analysing mesquite flour from both Prosopis species, in an early investigation, Felker et al. (2003) showed that $P$. pallida pods flour presented higher contents of protein

\footnotetext{
* Corresponding author.

E-mail address: ubarron@ipb.pt (U. Gonzales-Barron).
} 
(8.11\% db (dry base)) and fibre (3.40\% db), and lower content of fat $(0.77 \% \mathrm{db})$ than those of $P$. alba pod's flour $(7.17 \% \mathrm{db}, 2.40 \%$ and $2.17 \%$, respectively).

A recent broad study, carried out by the authors (Gonzales-Barron et al., 2020), characterised the nutritional quality and bioactive properties of $P$. pallida pod flour and its technological performance in breadmaking. Peruvian $P$. pallida flour was found to be a source of palmitic (12.6\%), oleic (35.5\%), and linoleic acids (45.8\%), $\alpha-, \beta-$, and $\gamma$ - tocopherols; and to have high contents of dietary fiber $(29.6 \% \mathrm{db})$ and protein $(9.5 \% \mathrm{dw})$ and lower content of total sugars $(18.3 \% \mathrm{dw})$ than the ones reported for $P$. alba flour (38.2\% dw; Felker et al., 2003).

Therefore, the objective of this study was to continue the aforementioned research by evaluating the effect of partially replacing wheat flour of high ash content (type 65) or low ash content (type 55) with $P$. pallida pod flour on the proximate composition and staling indicators of the composite bread.

\section{Materials and methods}

\subsection{Materials for bread-making and experimental design}

P. pallida (mesquite) flour derived from pod mesocarp was purchased from a food retailer (Nutrimix, Lima, Peru). The mesquite flour composition was $2.3 \pm 0.1$ of ash, $9.5 \pm 0.1$ protein, $1.0 \pm 0.1$ fat, $57.6 \pm 0.1$ carbohydrates and $29.6 \pm 0.2$ dietary fibre (all contents in $\mathrm{g} / 100 \mathrm{~g}$ dry weight). Mesquite flour was stored in a polyethylene container and maintained at room temperature prior to further processing ( $\left.\pm 20^{\circ} \mathrm{C}\right)$. Wheat white flours of type $55(11.0 \%$ protein, $0.51 \%$ ash) and type 65 ( $12.5 \%$ protein, $0.63 \%$ ash) were obtained from Loreto milling company (Bragança, Portugal). The terminology 55 and 65 is a German reference which is now becoming disseminated in Europe and indicates the amount of mineral residue in the ash. Type 55 typically has $55 \%$ of minerals while type 65 usually varies between 60 and $65 \%$. Both are used to make bread.

Refined and non-iodinated salt and dried yeast were purchased from a local supermarket (Bragança, Portugal). Tap water was employed to prepare the bread. A full two-factor design was employed, varying the replacement of wheat flour of either type 55 or 65 with mesquite flour $(0,5,10$ and $15 \% \mathrm{w} / \mathrm{w})$, which produced a total of 8 treatments repeated twice. Previous research showed that up to a substitution level of $10 \%$, the addition of Peruvian mesquite flour significantly increases loaf volume and produces a more uniform crumb aspect consisting of more alveoli of small size (Gonzales-Barron et al., 2020). For that reason, replacement levels higher than $15 \%$ were not tested in the present study.

\subsection{Bread-making process}

Bread loaves for all of the 8 treatments were prepared following the same method. For each batch, $\sim 1600 \mathrm{~g}$ of dough was prepared. Each batch was prepared by mixing the dry ingredients (wheat flour 55 or 65 , mesquite flour at $0,5,10$ or $15 \%$ total weight flour, $5 \%$ yeast and $1.5 \%$ salt) for $2 \mathrm{~min}$ at speed 2 using a batter blade in a professional food processor (SilverCrest SKMP-1200, Germany). Water (59.1\%) was added and mixed for $2 \mathrm{~min}$ at speed 1 followed by $7 \mathrm{~min}$ at speed 2 using a dough hook. The dough was then removed from the mixer and shaped as a cylinder and placed in a floured tray to proof as a whole for $60 \mathrm{~min}$ in a climate chamber at $37{ }^{\circ} \mathrm{C}$ and $85 \%$ relative humidity (RH) (Climacell 222, Germany). Then, the dough was carefully portioned into six $230 \pm 10 \mathrm{~g}$ balls and placed into oiled and floured tins. The tins had a base dimension of $12 \mathrm{~cm} \times 8 \mathrm{~cm}$. These were then placed in the same climate chamber $\left(37^{\circ} \mathrm{C}\right.$ and $\left.85 \% \mathrm{RH}\right)$ and allowed to proof for an additional $15 \mathrm{~min}$. Subsequently, the tins and trays were placed in a preheated convection oven (Princess, $2000 \mathrm{~W}$, The Netherlands) at $230{ }^{\circ} \mathrm{C}$ and baked for $40 \pm 0.5 \mathrm{~min}$. After baking, the bread loaves were removed from the tins and allowed to cool. They were then stored at $20{ }^{\circ} \mathrm{C}$ for a maximum of five days until analysis completion.

\subsection{Proximate composition of bread}

The nutritional composition of bread (proximate analysis, free sugars and fatty acids) was quantified one day after baking, using one bread loaf per treatment with essays in triplicate.

\subsubsection{Proximate analysis}

Proximate analysis (moisture, protein, fat, fibre and ash) was conducted in bread from all treatments using the AOAC official methods (AOAC, 2016).

Moisture was calculated following AOAC method 925.09, where $2 \mathrm{~g}$ were added to a dish and placed for $5 \mathrm{~h}$ in an oven at $100{ }^{\circ} \mathrm{C}$. The protein content $(\mathrm{N} \times 5.83)$ of the samples was estimated by the macroKjeldahl method (AOAC 920.87). Fat was determined by the Randall method (AOAC 2003.05; 4) replacing the diethyl ether with petroleum ether, using a Soxhlet apparatus. The ash content was determined by incineration at $550{ }^{\circ} \mathrm{C}$ for at least $8 \mathrm{~h}$ (AOAC 942.05). Fibre was calculated through the enzymatic-gravimetric method (AOAC 993.19). Total carbohydrates were calculated by difference. Energy was calculated according to the European Parliament and Council Regulation No. 1169/2011 formula:

$$
\begin{aligned}
\text { Energy }\left(\frac{k c a l}{100 g}\right)= & 4 \times(g \text { protein }+g \text { total available carbohydrates }) \\
& +2 \times(g \text { dietary fiber })+9 \times(g \text { fat })
\end{aligned}
$$

\subsubsection{Free sugars}

A High Performance Liquid Chromatography (HPLC) system, coupled to a refraction index detector (RI detector Knauer Smartline 2300, Berlin, Germany) was used to determine the free sugars in the bread samples, after an extraction procedure previously described in Barros et al. (2013). Sugars identification was performed by comparison to commercial standards $\mathrm{D}(-)$-fructose, $\mathrm{D}(+)$-glucose, $\mathrm{D}(+)$-sucrose, $\mathrm{D}$ $(+)$-trehalose and $\mathrm{D}(+)$-xylose (Sigma-Aldrich St. Louis, MI, USA) and quantification was based on the RI signal response of each standard. The chromatographic separation was achieved with a Eurospher $100-5$ $\mathrm{NH}_{2}$ column $\left(5 \mu \mathrm{m}, 250 \mathrm{~mm} \times 4.6 \mathrm{~mm}\right.$ i.d., Knauer) operating at $35^{\circ} \mathrm{C}$ (7971 R Grace oven). The mobile phase was acetonitrile (HPLC purity)/ deionized water, 70:30 ( $\mathrm{v} / \mathrm{v})$ at a flow rate of $1 \mathrm{~mL} / \mathrm{min}$ and the injection volume was $20 \mu$ l. Quantification was based on the internal standard method, using melezitose (HPLC purity) as the internal standard, and relying on calibration curves, obtained from commercial standards of each compound. Results were expressed in $\mathrm{g}$ per $100 \mathrm{~g}$ of dry weight.

\subsubsection{Fatty acids}

The analysis was performed through gas chromatography coupled to a flame ionisation detector (GC-FID) with prior transesterifications to fatty acid methyl esters (FAME) after a lipid extraction of the sample (3 g) using a Soxhlet apparatus with petroleum ether as previously described by Barros et al. (2013). The GC-FID was a YOUNG IN Chromass 6500 (Gyeonggi-do, South Korea) system, equipped with a split/ splitless injector set at $250{ }^{\circ} \mathrm{C}$ with a split ratio of $1: 80$, a flame ionization detector (FID) set at $260{ }^{\circ} \mathrm{C}$ and a Zebron-Fame column (20 mm $\times 0.18 \mathrm{~mm}$ ID $\times 0.15 \mu \mathrm{m}$ df, Phenomenex, Lisbon, Portugal). The following oven temperature program was used: initial temperature of $80{ }^{\circ} \mathrm{C}$, held for $1.5 \mathrm{~min}$, increase $40{ }^{\circ} \mathrm{C} / \mathrm{min}$ to $160{ }^{\circ} \mathrm{C}$, followed by a $5{ }^{\circ} \mathrm{C} / \mathrm{min}$ ramp to $185^{\circ} \mathrm{C}, 30{ }^{\circ} \mathrm{C} / \mathrm{min}$ ramp to $260^{\circ} \mathrm{C}$ and held for $4 \mathrm{~min}$. The carrier gas (hydrogen) flow-rate was $0.6 \mathrm{~mL} / \mathrm{min}$, measured at $250{ }^{\circ} \mathrm{C}$. For each analysis $1 \mu \mathrm{l}$ of the sample was injected in GC. Fatty acids identification and quantification was performed by comparing the relative retention times of FAME peaks from samples with standards (standard mixture 47885-U, Sigma, St. Louis, USA) and results were 
Table 1

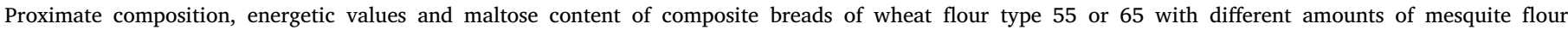
$($ mean $\pm \mathrm{SD})$.

\begin{tabular}{|c|c|c|c|c|c|c|c|c|c|}
\hline \multirow[b]{2}{*}{ Mesquite (\%) } & \multicolumn{5}{|c|}{ Flour 55} & \multicolumn{4}{|c|}{ Flour 65} \\
\hline & $0 \%$ & & $5 \%$ & $10 \%$ & $15 \%$ & $0 \%$ & $5 \%$ & $10 \%$ & $15 \%$ \\
\hline \multicolumn{10}{|c|}{ Nutritional value $(\mathrm{g} / 100 \mathrm{~g} \mathrm{fw})$} \\
\hline Moisture (\%) & $33.8 \pm 0.2^{\mathrm{a}}$ & 35.9 & $\pm 0.9^{\mathrm{a}}$ & $35 \pm 2.1^{\mathrm{a}}$ & $35 \pm 1.2^{\mathrm{a}}$ & $37.5 \pm 0.9^{\mathrm{b}}$ & $34.7 \pm 0.5^{\mathrm{a}}$ & $34.2 \pm 0.7^{\mathrm{a}}$ & $35.0 \pm 0.5^{\mathrm{a}}$ \\
\hline Ash & $1.31 \pm 0.04^{\mathrm{a}}$ & 1.21 & $\pm 0.06^{\mathrm{a}}$ & $1.22 \pm 0.04^{\mathrm{a}}$ & $1.63 \pm 0.05^{\mathrm{b}}$ & $1.36 \pm 0.06^{\mathrm{a}}$ & $1.57 \pm 0.09^{\mathrm{b}}$ & $1.60 \pm 0.03^{b}$ & $1.58 \pm 0.04^{\mathrm{b}}$ \\
\hline Proteins & $7.4 \pm 0.13^{\mathrm{a}}$ & 7.53 & $\pm 0.02^{\mathrm{a}}$ & $7.40 \pm 0.05^{\mathrm{a}}$ & $7.8 \pm 0.11^{\mathrm{b}}$ & $7.59 \pm 0.08^{b}$ & $7.4 \pm 0.22^{\mathrm{a}}$ & $7.84 \pm 0.06^{c}$ & $7.83 \pm 0.07^{c}$ \\
\hline Fat & $1.07 \pm 0.02^{\mathrm{b}}$ & 1.03 & $\pm 0.05^{\mathrm{b}}$ & $0.95 \pm 0.01^{\mathrm{a}}$ & $0.97 \pm 0.03^{\mathrm{a}}$ & $0.57 \pm 0.05^{\mathrm{a}}$ & $0.62 \pm 0.04^{\mathrm{a}}$ & $0.96 \pm 0.01^{\mathrm{b}}$ & $0.85 \pm 0.05^{\mathrm{c}}$ \\
\hline Carbohydrates & $56.0 \pm 0.8^{\mathrm{a}}$ & 54.3 & $\pm 0.9^{\mathrm{a}}$ & $55 \pm 2.0^{\mathrm{a}}$ & $55 \pm 1.2^{\mathrm{a}}$ & $53.2 \pm 0.5^{\mathrm{a}}$ & $53 \pm 1.1^{\mathrm{a}}$ & $55.3 \pm 0.7^{\mathrm{b}}$ & $55.5 \pm 0.4^{\mathrm{b}}$ \\
\hline Energy (kcal/100 g fw) & $368 \pm 3^{b}$ & 356 & $\pm 4^{\mathrm{a}, \mathrm{b}}$ & $354 \pm 6^{\mathrm{a}}$ & $351 \pm 5^{\mathrm{a}}$ & $359 \pm 4^{\mathrm{b}, \mathrm{c}}$ & $348 \pm 2^{\mathrm{a}}$ & $353 \pm 3^{\mathrm{a}}$ & $360 \pm 2^{c}$ \\
\hline Total Dietary Fibre & $1.9 \pm 0.1^{\mathrm{a}}$ & 2.60 & $\pm 0.06^{\mathrm{b}}$ & $3.9 \pm 0.06^{\mathrm{b}, \mathrm{c}}$ & $4.11 \pm 0.03^{c}$ & $2.26 \pm 0.01^{\mathrm{a}}$ & $2.62 \pm 0.01^{\mathrm{a}, \mathrm{b}}$ & $2.91 \pm 0.06^{\mathrm{b}}$ & $4.0 \pm 0.3^{\mathrm{c}}$ \\
\hline Insoluble Fibre & $1.7 \pm 0.11^{\mathrm{a}}$ & 2.05 & $\pm 0.07^{\mathrm{b}}$ & $1.8 \pm 0.10^{\mathrm{a}}$ & $2.08 \pm 0.09^{c}$ & $1.5 \pm 0.12^{\mathrm{b}}$ & $1.85 \pm 0.03^{\mathrm{b}}$ & $1.03 \pm 0.03^{\mathrm{a}}$ & $2.2 \pm 0.30^{c}$ \\
\hline Soluble Fibre & $0.21 \pm 0.01^{\mathrm{a}}$ & 0.63 & $\pm 0.01^{\mathrm{b}}$ & $2.2 \pm 0.06^{c}$ & $2.1 \pm 0.11^{c}$ & $0.70 \pm 0.02^{\mathrm{a}}$ & $0.92 \pm 0.03^{\mathrm{b}}$ & $1.8 \pm 0.12^{\mathrm{c}}$ & $1.82 \pm 0.02^{\mathrm{c}}$ \\
\hline \multicolumn{10}{|l|}{ Free $\operatorname{sugar}(g / 100 \mathrm{~g} \mathrm{fw})$} \\
\hline Maltose & $0.99 \pm 0.01^{\mathrm{a}}$ & 1.05 & $\pm 0.05^{\mathrm{a}, \mathrm{b}}$ & $1.07 \pm 0.03^{\mathrm{b}}$ & $1.05 \pm 0.02^{\mathrm{a}, \mathrm{b}}$ & $0.80 \pm 0.03^{\mathrm{a}}$ & $0.98 \pm 0.01^{\mathrm{b}}$ & $1.07 \pm 0.01^{\mathrm{c}}$ & $1.08 \pm 0.02^{\mathrm{c}}$ \\
\hline
\end{tabular}

${ }^{\mathrm{a}, \mathrm{b}, \mathrm{c}}$ Different superscript letters indicate statistical significance at $\alpha=0.05$. Each flour type was evaluated independently.

recorded and processed using the Software Clarity DataApex 4.0 Software (Prague, Czech Republic) and expressed in relative percentage of each fatty acid.

\subsection{Bread staling indicators}

To evaluate bread staling, water activity and texture of crumb were quantified on days 1, 3 and 5 after baking, while mould and yeasts were essayed only on day 5 of storage. Two bread loaves were used per time point, one loaf for measuring water activity (in triplicate) and yeast/ mould concentration (in triplicate), and the other loaf for essaying a texture profile analysis (TPA) (replicated four times).

\subsubsection{Water activity}

Measurements of the water activity $\left(\mathrm{a}_{\mathrm{w}}\right)$ of the bread crumb were obtained according to Machado-Alencar, Steel, Alvim, Morais, and Andre-Bolini (2015) at $20{ }^{\circ} \mathrm{C}$ with the use of an Aqualab equipment (4TE Decagon, USA). $a_{w}$ was measured on each of the three central slices of the bread loaf, and results were averaged.

\subsubsection{Bread crumb texture}

A 30-kg load cell was used for calibration of a texture analyser TAXT plus, implemented with Exponent software version 6.1.11.0 (Stable Micro Systems, UK). A 50-mm diameter dough cutter was used to cut off a crumb cylinder from the centre of four slices per bread loaf. Thus, for each loaf, four texture profile analysis (TPA) repetitions were performed. A $40 \mathrm{~mm}$-diameter probe was fitted to the texture analyser (Rinaldi, Paciulli, Caligiani, Scazzina, \& Chiavaro, 2017). The parameters for the test were set at: pre-test speed $1 \mathrm{~mm} / \mathrm{s}$, test speed $2 \mathrm{~mm} / \mathrm{s}$ and post-test speed $2 \mathrm{~mm} / \mathrm{s}$, trigger force $5 \mathrm{~g}, 50 \%$ sample deformation (strain) and double compression (with a $30 \mathrm{~s}$ interval between cycles). The TPA parameters obtained were: hardness ( $g$ ) and resilience (dimensionless). For the characterisation of bread crumb texture, only two TPA descriptors were recorded: hardness and resilience. On the day of analysis, bread slices of $15-\mathrm{mm}$ thick were cut from two loaves per treatment using an electric slicer (Bosch MAS4000W, Germany). The first and last two slices of each loaf were discarded.

\subsubsection{Quantification of moulds and yeasts}

Ten-fold dilutions of $10 \mathrm{~g}$ bread crumb homogenised (Interscience Bag Mixer 400, France) for $60 \mathrm{~s}$ in $90 \mathrm{~mL}$ buffered peptone water (Liofilchem, Roseto degli Abruzzi, Italy) were prepared. One-ml aliquots were inoculated onto $3 \mathrm{M}^{\mathrm{TM}}$ Petrifilm ${ }^{\mathrm{TM}}$ Yeast and Mold Count plates ( $3 \mathrm{M}, \mathrm{MN}, \mathrm{USA})$. After 5 days of incubation at $20{ }^{\circ} \mathrm{C}$, yeasts and moulds were counted. Yeasts appeared as blue or green defined colonies while moulds colonies were more diffuse, larger and dark.

\subsection{Statistical analysis}

Regarding the proximate composition, all samples are presented as mean \pm standard deviation. A simple one-way analysis of variance was carried out, using Tukey's test (homoscedastic) or Tahmane T2 (non-homoscedastic) to classify the samples, with a prior accession of their homoscedasticity by means of a Levene's test.

For the shelf-life data, analysis was performed separately by wheat flour type. Hardness, Resilience or $\mathrm{a}_{\mathrm{w}}$ (generally represented by $y$ ) of a given treatment was modelled as:

$y=\beta_{0}+\beta_{1} \times$ Mesquite $+\beta_{2} \times$ Day $+\beta_{3} \times($ Mesquite $\times$ Day $)$

where $\beta_{0}$ is the intercept, $\beta_{1}$ the effect of the level of mesquite replacement, $\beta_{2}$ the effect of the day of storage, and $\beta_{3}$ the interaction between mesquite level replacement and day. The interaction term $\beta_{3}$ allowed testing whether the deterioration rate $\beta_{2}$ (hardening rate if $\mathrm{y}=$ hardness; resilience loss rate if $\mathrm{y}=$ resilience; or drying rate $\mathrm{y}=\mathrm{a}_{\mathrm{w}}$ ) is regulated by the mesquite replacement level. Significance of fixed effects was assessed by analysis of variance at $\alpha=0.05$. Models were fitted and charts designed in R studio 1.0.136 implemented in $\mathrm{R}$ version 3.3.2.

\section{Results and discussion}

\subsection{Macronutrient quality of wheat-mesquite flour composite bread}

Comparing the different amounts of mesquite in the type 55 wheat flour bread, the treatment with $0 \%$ of mesquite flour showed the lowest values for all nutrients, as well as for maltose (Table 1). Still, no statistical differences were found among the treatments regarding moisture, which was reported between 33.8 and $35 \mathrm{~g} / 100 \mathrm{~g} \mathrm{dw}$. Regarding ash and proteins, the only statistical difference was found for the treatment with $15 \%$ mesquite flour, which showed higher quantities. Similar results were previously reported by Bigne et al. (2016a,b) using a replacement fraction of $15 \%$ mesquite flour (2.23 and $9.61 \mathrm{~g} /$ $100 \mathrm{~g}$, respectively). Regarding fat, the higher the mesquite amount the lower the fat content, with 10 and $15 \%$ enriched bread showing significantly lower amounts. This was expected as the fat content of Peruvian mesquite flour is low $(1.0 \pm 0.1 \mathrm{~g} / 100 \mathrm{~g} \mathrm{dw})$, as reported in our previous study (Gonzales-Barron et al., 2020).

Carbohydrates showed no statistical difference regardless of the mesquite amount added to the bread. In terms of the energetic value, it seems that the breads with mesquite flour had lower values when compared to wheat flour, which translated into a significant lower energy with the increase of mesquite flour. By contrast, fibre, both soluble and insoluble increased with the addition of mesquite flour 
(using flour type 55, addition of mesquite flour produced an increase of $116 \%$ in Total Dietary Fiber), showing the beneficial health effects that this type of flour can provide. This means that composite wheat-mesquite breads could support the claim "source of fibre", according to the provisions of European Parliament and European Council (Regulation (EC) $n^{\circ} 1924 / 2006$ ), which establish a minimum of $3 \mathrm{~g} / 100 \mathrm{~g}$. In fact, the mesquite flour used in this study was found to have high total dietary fibre at $29.6 \pm 0.2 \mathrm{~g} / 100 \mathrm{~g} \mathrm{dw}$, split into $26.3 \pm 0.4 \mathrm{~g} / 100 \mathrm{~g}$ $\mathrm{dw}$ for insoluble fibre and $3.3 \pm 0.2 \mathrm{~g} / 100 \mathrm{~g} \mathrm{dw}$ for soluble fibre (Gonzales-Barron et al., 2020).

Maltose, a soluble sugar found in bread due to the breakdown of starch by $\alpha$-amylase, also showed a significant increase with the amount of mesquite flour. Total sugars of Peruvian mesquite flour were quantified at $18.3 \pm 0.2 \mathrm{~g} / 100 \mathrm{~g} \mathrm{dw}$ in the previous study (GonzalesBarron et al., 2020).

With regards to the wheat flour type 65 , the sample without mesquite showed a significantly higher amount of moisture, while the samples with mesquite did not show any differences. Ash and protein contents increased as mesquite level of replacement was higher, as can be seen in the type 55 wheat flour breads. The same increase was also detected for carbohydrates, although the samples with higher amounts of mesquite flour (10 and 15\%) were significantly different from the 5 and $0 \%$ mesquite formulations. The energy values, although showing some inconsistent values, varied very slightly from 348 to $360 \mathrm{kcal}$. Once again, a significant increase in fibre content was detected, although there were variations among the soluble and insoluble fractions.

Overall, the addition of mesquite flour in formulations with wheat flour type 65 increased the contents of protein, fat, carbohydrates and dietary fibre of composite breads, and it also increased fibre and reduced fat when blended with wheat flour type 55 .

\subsection{Fatty acid profile of wheat-mesquite flour composite bread}

Although twelve fatty acids are presented in Table 2 , sixteen were detected, but their amounts were $<1 \%$ and so they were disregarded. These four fatty acids were caprylic acid (C8:0), capric acid (C10:0), lauric acid (C12:0) and pentadecanoic acid (C15:0). The most abundant fatty acid in all samples was palmitic acid (C16:0) followed by oleic acid (C18:1) (Table 2). This may be due to the fact that Peruvian mesquite flour is rich in palmitic (12.6\%) and oleic (35.5\%) acids, as found in our previous investigation (Gonzales-Barron et al., 2020).
Although there were some variations among the individual fatty acids, the most important conclusions regarding these compounds are the variations of the saturated and unsaturated ones. Regarding the breads with wheat flour type 55, the statistically higher amounts of saturated fatty acids (SFA) were found for the 0 and $5 \%$ incorporated breads, and the lowest SFA contents in the 10 and $15 \%$ mesquite added breads. On the contrary, the polyunsaturated fatty acids (PUFA) increased significantly with the increase of mesquite flour, while no difference was detected for the monounsaturated fatty acids (MUFA), which did not vary significantly with the increase of mesquite flour. Wheat flour 65 showed very similar results, with a gradual but significant decrease of SFA and an increase in MUFA and PUFA. These results show that mesquite flour can provide composite breads with healthy unsaturated fatty acids. According to Giaretta, Lima, and Carpes (2018), the addition of chia and kinako flour in bread improved the profile of unsaturated fatty acids and omega 6/omega 3, and the amounts of fatty acids in the heating process did not cause significant changes in the fatty acid profile.

\subsection{Staling indicators of wheat-mesquite flour composite bread}

According to Gray and Bemiller (2003), the phenomena behind bread staling are moisture loss and starch retrogradation, which harden the crumb. In addition, bread is also subject to microbiological deterioration, mainly through mould and yeast spoilage (Axel, Zannini, \& Arendt, 2017). Thus, to assess the quality loss of bread during storage, three properties were measured - water activity, texture of crumb and moulds/yeasts counts.

\subsubsection{Water activity of bread crumb}

The water activity of wheat-mesquite composite bread decreases with crumb aging for both wheat flour types, as illustrated in Fig. 1, and also demonstrated by the significant negative effects of Day for wheat flour type $65\left(\beta_{2}=-0.0083, \mathrm{p}<0.001\right.$ in Table 3$)$ and wheat flour type $55\left(\beta_{2}=-0.0174\right.$ with $\mathrm{p}<0.001$ in Table 4). Likewise, regardless of the wheat flour type, the effect of the level of mesquite flour on bread crumb water activity was the inverse: $\beta_{1}=-0.0047$ with $\mathrm{p}=0.003$ for wheat flour type 65 (Table 3 ) and $\beta_{1}=-0.0054$ with $\mathrm{p}=0.003$ for wheat flour type 55 (Table 4). This suggests that greater additions of mesquite flour tend to decrease the water activity of the bread crumb.

Table 2

Fatty acid profile of composite bread of wheat flour type 55 or 65 with different amounts of mesquite flour (mean \pm DE).

\begin{tabular}{|c|c|c|c|c|c|c|c|c|c|}
\hline \multirow[b]{2}{*}{ Mesquite (\%) } & \multicolumn{4}{|c|}{ Flour 55} & \multicolumn{5}{|c|}{ Flour 65} \\
\hline & $0 \%$ & $5 \%$ & $10 \%$ & $15 \%$ & $0 \%$ & & $5 \%$ & $10 \%$ & $15 \%$ \\
\hline \multicolumn{10}{|c|}{ Fatty Acids (\%) } \\
\hline C6:0 & $0.63 \pm 0.02^{\mathrm{a}}$ & $1.17 \pm 0.02^{\mathrm{b}}$ & $2.01 \pm 0.04^{\mathrm{d}}$ & $1.65 \pm 0.03^{c}$ & $0.73 \pm 0.02^{\mathrm{a}}$ & 0.63 & $\pm 0.04^{\mathrm{b}}$ & $0.83 \pm 0.02 c$ & $0.85 \pm 0.03^{\mathrm{c}}$ \\
\hline $\mathrm{C} 14: 0$ & $0.187 \pm 0.003^{\mathrm{b}}$ & $0.24 \pm 0.02^{\mathrm{c}}$ & $0.124 \pm 0.001^{\mathrm{a}}$ & $0.109 \pm 0.002^{\mathrm{a}}$ & $2.31 \pm 0.08^{\mathrm{a}}$ & 2.31 & $\pm 0.01^{\mathrm{a}}$ & $2.15 \pm 0.07^{b}$ & $1.96 \pm 0.01^{\mathrm{a}}$ \\
\hline C16:0 & $41.6 \pm 0.2^{\mathrm{a}}$ & $41.9 \pm 0.4^{\mathrm{a}}$ & $41.5 \pm 0.3^{\mathrm{a}}$ & $41.3 \pm 0.3^{\mathrm{a}}$ & $41.6 \pm 0.1^{\mathrm{a}, \mathrm{b}}$ & 42.5 & $5 \pm 0.3^{c}$ & $41.9 \pm 0.2^{\mathrm{b}}$ & $41.1 \pm 0.2^{\mathrm{a}}$ \\
\hline $\mathrm{C} 16: 1$ & $0.94 \pm 0.01^{\mathrm{a}}$ & $1.04 \pm 0.04^{\mathrm{a}}$ & $1.4 \pm 0.1^{\mathrm{b}}$ & $0.931 \pm 0.007^{\mathrm{a}}$ & $1.27 \pm 0.01^{\mathrm{a}}$ & 1.24 & $\pm 0.01^{\mathrm{a}}$ & $1.91 \pm 0.04^{\mathrm{c}}$ & $1.68 \pm 0.01^{\mathrm{b}}$ \\
\hline $\mathrm{C} 17: 0$ & $7.41 \pm 0.05^{\mathrm{a}, \mathrm{b}}$ & $7.75 \pm 0.08^{\mathrm{c}}$ & $7.6 \pm 0.2^{\mathrm{b}, \mathrm{c}}$ & $7.28 \pm 0.02^{\mathrm{b}}$ & $4.6 \pm 0.4^{\mathrm{b}}$ & 3.58 & $\pm 0.02^{\mathrm{a}}$ & $4.11 \pm 0.06^{\mathrm{a}, \mathrm{b}}$ & $4.33 \pm 0.04^{\mathrm{b}}$ \\
\hline $\mathrm{C} 18: 0$ & $9.85 \pm 0.05^{c}$ & $8.31 \pm 0.07^{b}$ & $7.6 \pm 0.3^{\mathrm{a}}$ & $7.67 \pm 0.06^{\mathrm{a}}$ & $12.7 \pm 0.1^{\mathrm{a}, \mathrm{b}}$ & 13.8 & $3 \pm 0.2^{c}$ & $13.1 \pm 0.2^{\mathrm{b}}$ & $12.5 \pm 0.05^{\mathrm{a}}$ \\
\hline $\mathrm{C} 18: 1 \mathrm{n} 9 \mathrm{c}$ & $31.4 \pm 0.2^{\mathrm{b}}$ & $30.4 \pm 0.1^{\mathrm{a}}$ & $30.1 \pm 0.5^{\mathrm{a}}$ & $30.7 \pm 0.3^{\mathrm{b}, \mathrm{a}}$ & $31.58 \pm 0.06^{\mathrm{b}}$ & 30.76 & $5 \pm 0.01^{a}$ & $32.44 \pm 0.08^{c}$ & $33.29 \pm 0.08^{\mathrm{d}}$ \\
\hline $\mathrm{C} 18: 2 \mathrm{n} 6 \mathrm{c}$ & $2.37 \pm 0.01^{\mathrm{a}}$ & $2.26 \pm 0.001^{\mathrm{a}}$ & $3.6 \pm 0.1^{\mathrm{b}}$ & $3.93 \pm 0.02^{\mathrm{c}}$ & $0.55 \pm 0.01^{\mathrm{a}}$ & 0.56 & $\pm 0.01^{\mathrm{a}}$ & $0.55 \pm 0.01^{\mathrm{a}}$ & $0.62 \pm 0.01^{\mathrm{b}}$ \\
\hline $\mathrm{C} 20: 0$ & $1.05 \pm 0.06^{\mathrm{a}}$ & $1.17 \pm 0.01^{\mathrm{b}}$ & $1.17 \pm 0.04^{\mathrm{b}}$ & $1.267 \pm 0.008^{\mathrm{b}}$ & $0.89 \pm 0.01^{\mathrm{a}}$ & 0.803 & $\pm 0.002^{\mathrm{c}}$ & $0.250 \pm 0.004^{\mathrm{a}}$ & $0.75 \pm 0.01^{\mathrm{b}}$ \\
\hline C20:1 & $0.955 \pm 0.001^{\mathrm{a}}$ & $0.944 \pm 0.03^{\mathrm{a}}$ & $1.01 \pm 0.06^{\mathrm{a}}$ & $0.96 \pm 0.02^{\mathrm{a}}$ & $0.909 \pm 0.007^{\mathrm{b}}$ & 0.66 & $\pm 0.04^{\mathrm{a}}$ & $0.638 \pm 0.002^{\mathrm{a}}$ & $0.62 \pm 0.02^{\mathrm{a}}$ \\
\hline $\mathrm{C} 22: 0$ & $1.18 \pm 0.01^{\mathrm{b}}$ & $1.87 \pm 0.06^{\mathrm{d}}$ & $0.82 \pm 0.05^{\mathrm{a}}$ & $1.55 \pm 0.02^{\mathrm{c}}$ & $1.03 \pm 0.07^{\mathrm{c}}$ & 1.07 & $\pm 0.07^{\mathrm{d}}$ & $0.50 \pm 0.02^{\mathrm{a}}$ & $0.70 \pm 0.01^{\mathrm{b}}$ \\
\hline $\mathrm{C} 24: 0$ & $1.25 \pm 0.04^{b}$ & $1.358 \pm 0.005^{\mathrm{c}}$ & $1.25 \pm 0.03^{\mathrm{b}}$ & $0.975 \pm 0.05^{\mathrm{a}}$ & $0.60 \pm 0.01^{c}$ & 0.70 & $\pm 0.03^{d}$ & $0.349 \pm 0.003^{\mathrm{a}}$ & $0.485 \pm 0.002^{\mathrm{b}}$ \\
\hline SFA & $64.2 \pm 0.2^{\mathrm{b}}$ & $65.3 \pm 0.1^{b}$ & $63.8 \pm 0.8^{\mathrm{a}}$ & $63.4 \pm 0.3^{\mathrm{a}}$ & $65.68 \pm 0.04^{c}$ & 66.77 & $7 \pm 0.02^{\mathrm{d}}$ & $64.5 \pm 0.1^{\mathrm{b}}$ & $63.78 \pm 0.04^{\mathrm{a}}$ \\
\hline MUFA & $33.4 \pm 0.2^{\mathrm{a}}$ & $32.4 \pm 0.1^{\mathrm{a}}$ & $32.5 \pm 0.7^{\mathrm{a}}$ & $32.6 \pm 0.2^{\mathrm{a}}$ & $33.76 \pm 0.05^{\mathrm{b}}$ & 32.67 & $7 \pm 0.01^{\mathrm{a}}$ & $35.0 \pm 0.1^{\mathrm{c}}$ & $35.60 \pm 0.06^{\mathrm{d}}$ \\
\hline PUFA & $2.38 \pm 0.01^{\mathrm{a}}$ & $2.262 \pm 0.001^{\mathrm{a}}$ & $3.6 \pm 0.1^{\mathrm{b}}$ & $3.93 \pm 0.02^{\mathrm{c}}$ & $0.552 \pm 0.009^{\mathrm{a}}$ & 0.562 & $\pm 0.008^{\mathrm{a}}$ & $0.55 \pm 0.01^{\mathrm{a}}$ & $0.62 \pm 0.01^{\mathrm{b}}$ \\
\hline
\end{tabular}

nd - not detected. Caproic acid (C6:0); myristoleic acid (C14:0); Palmitic acid (C16:0); Palmitoleic acid (C16:1); Heptadecanoic acid (C17:0); Stearic acid (C18:0); Oleic acid (C18:1n9); Linoleic acid (C18:2n6); Arachidic acid (C20:0); Eicosenoic acid (C20:1); Behenic acid (C22:0); Lignoceric acid (C24:0). SFA- Saturated fatty acids; MUFA- Monounsaturated fatty acids; PUFA - Polyunsaturated fatty acids. ${ }^{\text {a,b,c,d }}$ Different superscript letters indicate statistical significance at $\alpha=0.05$. Each flour type was evaluated independently. 

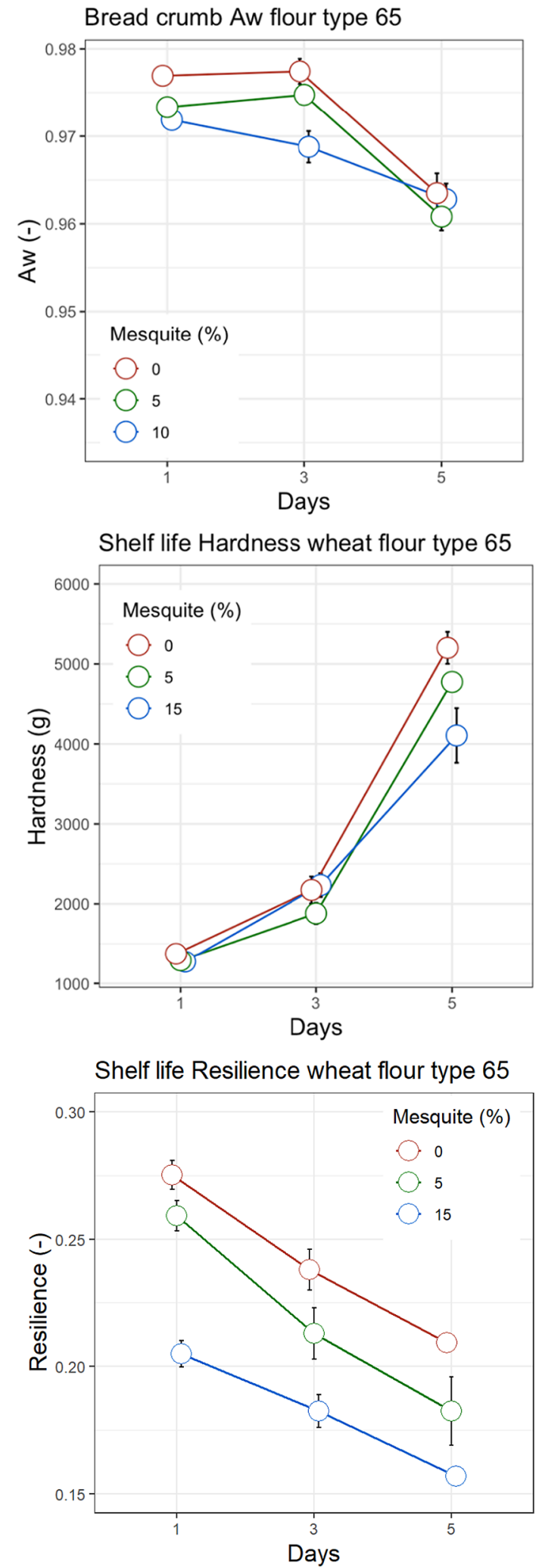

Bread crumb Aw flour type 55

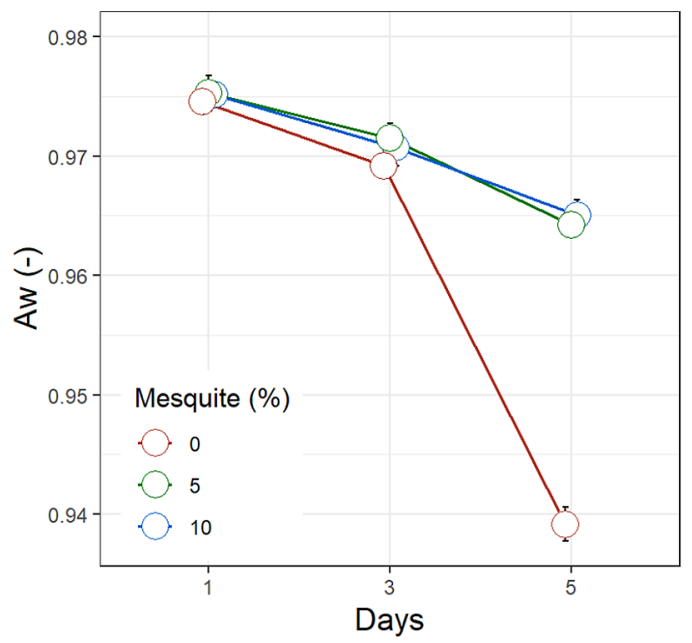

Shelf life Hardness wheat flour type 55

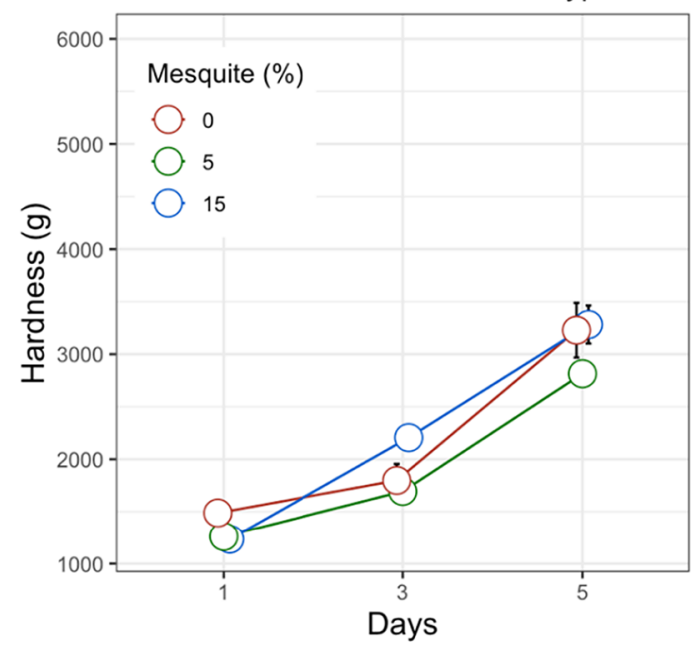

Shelf life Resilience wheat flour type 55

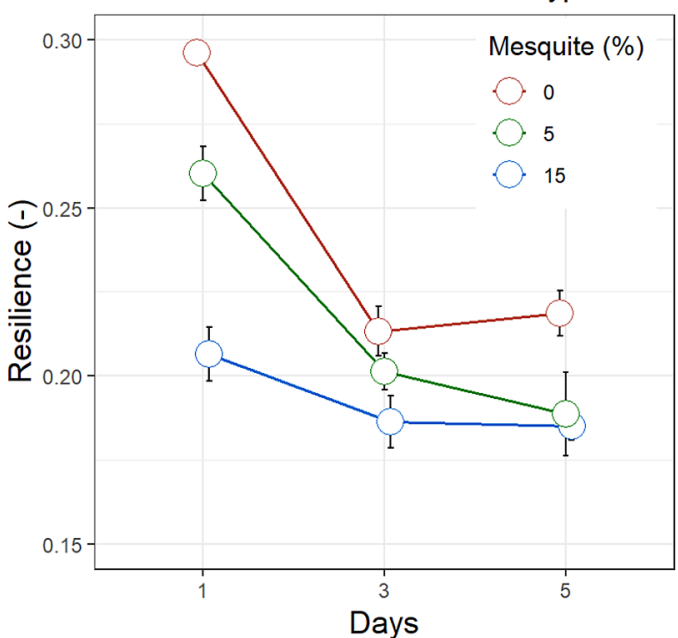

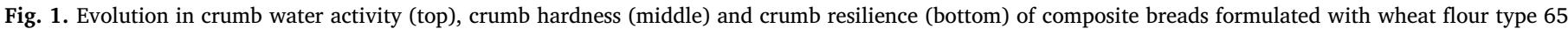
(left) or 55 (right), as affected by mesquite flour substitution level.

The increased fibre content due to mesquite flour addition favours water entrapment (Curti, Carini, Bonacini, Tribuzio, \& Vittadini, 2013). In addition, an early study by Zolfaghari, Harden and Huffman (1986) estimated that mesquite flour can have an absorption capacity of up to $150 \%$, and they attributed it mainly to the presence of mesquite gums and their chemical structure. Particularly, the galactomannan gum present in mesquite flour could interact with gluten proteins in dough (Correa et al., 2017). Thus, the decrease in crumb water activity (or amount of free water) with higher levels of mesquite flour, would be an effect of the greater water retaining capacity of hydrocolloids and fibre 
Table 3

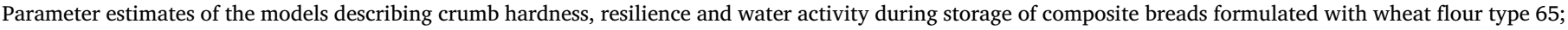
along with analyses of variance.

\begin{tabular}{|c|c|c|c|c|c|c|}
\hline \multirow[t]{2}{*}{ Parameter } & \multicolumn{2}{|l|}{ Hardness } & \multicolumn{2}{|l|}{ Resilience } & \multicolumn{2}{|c|}{ Water activity } \\
\hline & Estimate & $\mathrm{P}$-value & Estimate & P-value & Estimate & P-value \\
\hline Intercept $\left(\beta_{0}\right)$ & 6.802 & $<0.001$ & -1.195 & $<0.001$ & -0.0090 & 0.008 \\
\hline Mesquite $\left(\beta_{1}\right)$ & 0.006 & 0.532 & -0.019 & $<0.001$ & -0.0047 & 0.003 \\
\hline Day $\left(\beta_{2}\right)$ & 0.337 & $<0.001$ & -0.078 & $<0.001$ & -0.0083 & $<0.001$ \\
\hline \multirow[t]{2}{*}{ Mesquite*Day $\left(\beta_{3}\right)$} & -0.002 & 0.501 & 0.001 & 0.575 & -0.0011 & 0.117 \\
\hline & F-value & P-value & F-value & P-value & F-value & P-value \\
\hline Mesquite & 0.808 & 0.374 & 249.4 & $<0.001$ & 18.63 & $<0.001$ \\
\hline Day & 433.8 & $<0.001$ & 391.4 & $<0.001$ & 111.01 & $<0.001$ \\
\hline Mesquite*Day & 0.461 & 0.501 & 0.319 & 0.575 & 2.540 & 0.117 \\
\hline
\end{tabular}

from increased proportions of mesquite flour for the same amount of water.

Fig. 1 suggests that, for both wheat flour types, the rate at which water activity diminishes (i.e., dehydration rate) increases in time. Water has to migrate from the centre of the crumb to the crust. For this migration to occur, a difference in water vapour pressure should be present as driving force. Therefore, in the first days, water mostly migrates from the outer parts of the crumb to the crust (and eventually to the air) and this outward migration slowly starts pulling water from inner parts of the bread. Nonetheless, the water activity drop pattern was different between wheat flour types (Fig. 1). For wheat flour type 65 , it was more marked that water was freer to move during the late phase of bread staling than during the early phase; even though there was no significant difference between the initial water activities of bread crumb from whear flour $65(0.972-0.978)$ and wheat flour 55 (0.974-0.976).

Unlike mesquite flour level and day, whose effects $\left(\beta_{1}, \beta_{2}\right)$ on water activity were negative for both wheat flour types, the interaction between day and mesquite flour level $\left(\beta_{3}\right)$ did not follow the same trend for the two wheat flour types: in composite breads of 65 wheat flour, increasing levels of mesquite flour did not appear to have an effect on the crumb dehydration rate ( $\mathrm{p}=0.117$ in Table 3$)$, whereas in composite breads of wheat flour 55 , higher levels of mesquite flour slowed down the dehydration rate $\left(\beta_{3}=0.0032 ; \mathrm{p}<0.001\right.$ in Table 4). Possibly, the protein and fibre content naturally present in wheat flour type 65 retains water to similar extent as mesquite flour, so the effect of adding more mesquite flour on the dehydration rate of the crumb is not so marked. By contrast, having wheat flour type 55 a lower content of fibre and protein, increasing mesquite flour doses makes a sizeable difference in terms of water holding capacity, resulting in a marked retardation of the dehydration rate of the crumb. Furthermore, Fig. 1 (top right) where breads formulated with only wheat flour type $55(0 \%$ mesquite level), the dehydration is the fastest, reaching on day 5 the lowest water activity level (0.939) among all treatments.

\subsubsection{Hardness and resilience of bread crumb}

Interestingly, the addition of mesquite flour did not affect the initial crumb hardness of composite breads formulated with either wheat flour type 65 ( $\mathrm{p}=0.501$; Table 3$)$ or type $55(\mathrm{p}=0.122$; Table 4$)$. These findings are in disagreement with those of Correa et al. (2017), who found that replacing $15 \%$ of wheat white flour with mesquite flour hardened the crumb from $4.0 \mathrm{~N}$ to $8.2 \mathrm{~N}$. They attributed it to the lower specific volume and the contribution of gums and proteins to form more structured cell walls in the crumb. Bigne et al. (2016a,b) suggest that mesquite flour promotes hardening at the initial stages. Nevertheless, it is worth mentioning that Correa et al. (2017) used mesquite flour from Prosopis alba pods while the mesquite flour used in the present study comes from $P$. pallida, a species whose pods have been proven to have a different composition (Felker et al., 2003).

By contrast, storage time did have a significant effect on crumb hardness ( $p<0.0001$ for wheat flour type 65 and 55), as can be appreciated in Fig. 1 where formulations with wheat flour type 65 and 55 show an exponentially increasing hardness over time. Yet, the effect of time (or hardening rate) was different between wheat flour types. Although on day 1 after baking, breads prepared with wheat flour type 65 and 55 presented comparable levels of hardness $(<1500 \mathrm{~g})$, as storage time progressed, breads formulated with wheat flour 65 became noticeably harder than those of wheat flour 55 (Fig. 1). On the third day of storage, mean crumb hardness values of wheat flour type 65 treatments (1860-2450 g) were numerically higher than those of wheat flour 55 ones (1605-2380 g); while, on the fifth day of storage, the difference in mean crumb hardness between wheat flour types reached statistical significance (4110-5250 g for wheat flour type 65 treatments versus 2865-3471 g for flour 55 treatments) (Fig. 1).

As with the water activity, when using wheat flour type 65 there was no effect of mesquite flour on bread crumb hardening rate ( $\mathrm{p}=0.501$ in Table 3), whereas, when using wheat flour type 55, a higher mesquite flour substitution level slowed down the hardening process $\left(\beta_{3}=-0.005\right.$ with $\mathrm{p}=0.028$ in Table 4$)$. Non-starch polysaccharides such as galactomannans have been reported to have an anti-staling mechanism (Schiraldi \& Fessas, 2001). The current belief is

Table 4

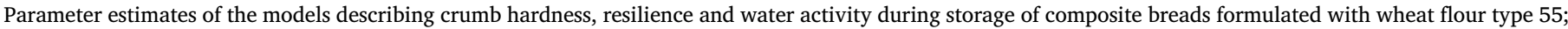
along with analyses of variance.

\begin{tabular}{|c|c|c|c|c|c|c|}
\hline \multirow[t]{2}{*}{ Parameter } & \multicolumn{2}{|l|}{ Hardness } & \multicolumn{2}{|l|}{ Resilience } & \multicolumn{2}{|c|}{ Water activity } \\
\hline & Estimate & P-value & Estimate & $\mathrm{P}$-value & Estimate & P-value \\
\hline Intercept $\left(\beta_{0}\right)$ & 7.023 & $<0.001$ & -1.171 & $<0.001$ & -0.0021 & 0.667 \\
\hline Mesquite $\left(\beta_{1}\right)$ & 0.009 & 0.183 & -0.025 & $<0.001$ & -0.0054 & 0.003 \\
\hline Day $\left(\beta_{2}\right)$ & 0.189 & $<0.001$ & -0.091 & $<0.001$ & -0.0174 & $<0.001$ \\
\hline \multirow[t]{2}{*}{ Mesquite*Day $\left(\beta_{3}\right)$} & -0.005 & 0.028 & 0.001 & 0.009 & 0.0032 & $<0.001$ \\
\hline & F-value & P-value & F-value & P-value & F-value & P-value \\
\hline Mesquite & 2.506 & 0.122 & 65.98 & $<0.001$ & 2.820 & 0.097 \\
\hline Day & 403.0 & $<0.001$ & 103.5 & $<0.001$ & 102.9 & $<0.001$ \\
\hline Mesquite*Day & 5.194 & 0.028 & 7.702 & 0.009 & 15.57 & $<0.001$ \\
\hline
\end{tabular}


that these compounds do not affect starch retrogradation, but act as molecular water sinks within the crumb matrix, where they would slowly release moisture in the course of shelf life. Because of its plasticising effect, the water released would keep the composite bread crumb softer for a longer time period. This interpretation is based on the finding that the galactomannans present in Peruvian $P$. pallida seeds $(13-14 \% \mathrm{wb})$ have a high molecular weight of $\sim 900000$ to 1000 000 Da (Chaires-Martínez, Salazar-Montoya, \& Ramos-Ramírez, 2008), which would enable the composite flour dough to entrap large amounts of water.

The TPA parameter related to bread crumb recovery after compression - resilience - was modified by the addition of mesquite flour in both wheat flour types, $65\left(\beta_{1}=-0.020\right.$ with $\mathrm{p}=0.003$ in Table 3$)$ and $55\left(\beta_{1}=-0.025\right.$ with $\mathrm{p}<0.001$ in Table 4$)$. The negative effect suggests that bread crumbs of lower resilience are produced with increasing mesquite flour substitution levels (Fig. 1). Chaires-Martínez et al. (2008) characterised the galactomannans of $P$. pallida seeds from the same geographical origin as the one used in this study, as having a non-Newtonian behaviour of shear thinning type (i.e., viscosity diminishes with increasing shearing rates) similar to locust bean gum and guar gum, but of higher apparent viscosity than those. In this way, the addition of mesquite flour to dough would confer more viscous properties rather than elastic ones as gluten.

Moreover, the crumb resilience of composite breads was also lost during storage, as shown in Fig. 1, and corroborated by statistical analysis in both wheat flour types ( $\mathrm{p}<0.001$ in Tables 3 and 4). Nonetheless, the profile of crumb resilience loss was different between wheat flour types (Fig. 1): when mesquite flour was blended with wheat flour type 65, the drop in resilience was inherently linear and did not seem to stabilise at least within the 5 days of storage. In contrast, the use of wheat flour type 55 favoured a stabilisation in crumb resilience, so that there were no significant differences in crumb resilience between the third and the fifth day of storage in any of the substitution levels with mesquite flour. While the loss of crumb resilience is a normal characteristic of bread staling, the resilience loss rate was lower in breads of increasing mesquite flour levels when blended with wheat flour type $55\left(\beta_{3}=0.001\right.$ with $\mathrm{p}=0.009$ in Table 4). It can be argued that the crumb resilience of breads with higher mesquite flour substitution, say $15 \%$, is so low right from the beginning that there might be little potential for further loss in resilience during storage (Fig. 1).

\subsubsection{Yeasts and moulds in bread crumb}

In most of the bread treatments, on the fifth day of storage, moulds were below or at the limit of quantification $(0.69 \log \mathrm{CFU} / \mathrm{g})$, except for the formulation of wheat flour type 55 substituted with $15 \%$ mesquite flour (1.18 log CFU/g) (Table 5). On the contrary, yeasts could be counted in all of the treatments, although they were not visible on the bread loaves on the fifth day of storage. At mesquite flour levels of $0 \%$ and $5 \%$, significantly higher counts of yeast $(\mathrm{p}<0.05)$ were found for wheat flour type 65 (3.45 and $3.60 \mathrm{log} \mathrm{CFU} / \mathrm{g}$ ) in comparison to wheat type 55 (3.05 and $3.40 \log \mathrm{CFU} / \mathrm{g}$ ). At the other levels of mesquite flour substitution, no significant differences were encountered between wheat flour types.

Furthermore, replacing wheat flour type 65 with different levels of mesquite flour did not have any impact on the yeasts counts (3.45 log $\mathrm{CFU} / \mathrm{g}$ for the control against 3.46-3.60 log CFU/g for the composite breads). However, the addition of mesquite flour to wheat flour type 55 produced a significant increase in the concentration of yeasts from 3.05 $\log \mathrm{CFU} / \mathrm{g}$ (0\% mesquite) to $3.40-3.55 \mathrm{log} \mathrm{CFU} / \mathrm{g}$ (composite breads) (Table 5). This may be linked to the increase in water activity that replacing wheat flour type 55 with mesquite flour produced in the resulting composite breads (Fig. 1).

\section{Conclusion}

The macronutrient quality of composite breads was enhanced by the
Table 5

Means and standard errors (SE) of yeasts and moulds numbers (log CFU/g) in composite bread of wheat flour type 55 or 65 with different substitution levels of mesquite flour, quantified on the 5 th day of storage at $20{ }^{\circ} \mathrm{C}$ and $55 \% \mathrm{RH}$.

\begin{tabular}{|c|c|c|c|c|}
\hline \multirow{2}{*}{$\begin{array}{l}\text { Wheat flour } \\
\text { Mesquite \% }\end{array}$} & \multicolumn{2}{|l|}{ Type 55} & \multicolumn{2}{|l|}{ Type 65} \\
\hline & Mean & SE & Mean & SE \\
\hline \multicolumn{5}{|l|}{ Yeasts } \\
\hline $0 \%$ & $3.05^{\mathrm{aA}}$ & 0.05 & $3.45^{\mathrm{aB}}$ & 0.13 \\
\hline $5 \%$ & $3.40^{\mathrm{bA}}$ & 0.12 & $3.60^{\mathrm{aB}}$ & 0.07 \\
\hline $10 \%$ & $3.55^{\mathrm{bA}}$ & 0.08 & $3.58^{\mathrm{aA}}$ & 0.03 \\
\hline $15 \%$ & $3.50^{\mathrm{bA}}$ & 0.11 & $3.46^{\mathrm{aA}}$ & 0.15 \\
\hline \multicolumn{5}{|l|}{ Moulds } \\
\hline $0 \%$ & $<0.69^{\mathrm{aA}}$ & $-^{c}$ & $<0.69^{\mathrm{aA}}$ & - \\
\hline $5 \%$ & $<0.69^{\mathrm{aA}}$ & - & $<0.69^{\mathrm{aA}}$ & - \\
\hline $10 \%$ & $<0.69^{\mathrm{aA}}$ & - & $0.69^{\mathrm{aA}}$ & 0.00 \\
\hline $15 \%$ & $1.18^{\mathrm{bA}}$ & 0.03 & $<0.69^{\mathrm{aA}}$ & - \\
\hline
\end{tabular}

a,b,A,B Different lower-case superscript letters indicate significant differences between mesquite flour substitution level, while different capital superscript letters indicate significant differences between flour type $(\alpha=0.05)$.

${ }^{\mathrm{c}}$ Not quantifiable since all replicates were below the limit of quantification (0.69 log CFU/g).

addition of Peruvian $P$. pallida pod flour, especially due to the increase of fibre and unsaturated fatty acids, when compared to the samples without any mesquite flour. In most cases, the higher the amount of mesquite flour, the higher the amount of total fibre and unsaturated fatty acids. This was corroborated in both the 55 and 65 wheat flour breads. Due to the water retaining capacity of galactomannans and fibre present in $P$. pallida pods, higher mesquite flour replacement levels produced bread crumb of decreased initial water activity. Nevertheless, in mixture with wheat flour type 55, the higher the mesquite flour level, the greater the water retained in the crumb during shelf life. The addition of mesquite flour (5-15\%) did not affect the initial crumb hardness of composite breads; yet it produced crumbs of significantly lower resilience. Mesquite flour did not retard crumb staling when mixed with wheat flour type 65 ; however, it did delay staling when blended with wheat flour type 55. Having wheat flour type 55 a lower content of fibre and protein, its supplementation with mesquite flour makes a sizeable difference in holding water capacity, which resulted in slower hardening, slower dehydration and slower loss in resilience of the composite bread crumb.

\section{CRediT authorship contribution statement}

Ursula Gonzales-Barron: Conceptualization, Formal analysis, Funding acquisition, Investigation, Methodology, Project administration, Resources, Software, Supervision, Visualization, Validation, Writing - original draft, Writing - review \& editing. Rody Dijkshoorn: Investigation, Methodology, Formal analysis, Validation, Writing original draft. Maikel Maloncy: Conceptualization, Project administration, Resources, Software, Supervision, Validation, Visualization. Tiane Finimundy: Investigation, Methodology, Writing - original draft, Validation, Visualization. Marcio Carocho: Investigation, Methodology, Writing - original draft, Writing - review \& editing, Validation, Visualization. Isabel C.F.R. Ferreira: Funding acquisition, Investigation, Methodology, Resources, Supervision, Visualization. Lillian Barros: Formal analysis, Funding acquisition, Investigation, Methodology, Project administration, Resources, Visualization, Supervision, Writing - original draft, Writing - review \& editing. Vasco Cadavez: Conceptualization, Formal analysis, Funding acquisition, Investigation, Methodology, Project administration, Resources, Software, Visualization, Supervision, Writing - original draft, Writing review \& editing. 


\section{Declaration of Competing Interest}

The authors declare that they have no known competing financial interests or personal relationships that could have appeared to influence the work reported in this paper.

\section{Acknowledgements}

The authors are grateful to the Foundation for Science and Technology (FCT, Portugal) for financial support through national funds FCT/MCTES to CIMO (UIDB/00690/2020); L. Barros, U. Gonzales-Barron and M. Carocho also thank the national funding by FCT, P.I., through the institutional and individual scientific employment program-contract for their contracts. The authors are also grateful to FEDER-Interreg España-Portugal programme for financial support through the project 0377_Iberphenol_6_E and TRANSCoLAB 0612_TRANS_CO_LAB_2_P.

\section{References}

AOAC. (2016). Official methods of analysis of AOAC international. In: George, W., and Jr. Latimer (Eds.) (20th Ed.) Gaithersburg, MD: AOAC International.

Axel, C., Zannini, E., \& Arendt, E. K. (2017). Mold spoilage of bread and its biopreservation: A review of current strategies for bread shelf life extension. Critical Reviews in Food Science and Nutrition, 57(16), 3528-3542.

Barros, L., Dueñas, M., Dias, M. I., Sousa, M. J., Santos-Buelga, C., \& Ferreira, I. C. F. R. (2013). Phenolic profiles of cultivated, in vitro cultured and commercial samples of Melissa officinalis L. infusions. Food Chemistry, 136(1), 1-8.

Bigne, F., Puppo, M. C., \& Ferrero, C. (2016a). Fibre enrichment of wheat flour with mesquite (Prosopis spp.): Effect on breadmaking performance and staling. LWT - Food Science and Technology, 65, 1008-1016.

Bigne, F., Puppo, M. C., \& Ferrero, C. (2016b). Rheological and microstructure characterization of composite dough with wheat and mesquite (Prosopis spp.) flours. International Journal of Food Properties, 19(2), 242-256.

Bigne, F., Puppo, M. C., \& Ferrero, C. (2018). Mesquite (Prosopis alba) flour as a novel ingredient for obtaining a "panettone-like" bread. Applicability of part-baking technology. LWT - Food Science and Technology, 89, 666-673.

Bigne, F., Romero, A., Ferrero, C., Puppo, M. C., \& Guerrero, A. (2017). Rheological and microstructural study of wheat doughs partially replaced with mesquite flour (Prosopis alba) and added with transglutaminase. Food Bioprocessing Technology, 10,
819-830.

Chaires-Martínez, L., Salazar-Montoya, J. A., \& Ramos-Ramírez, E. G. (2008). Physicochemical and functional characterisation of the galactomannan obtained from mesquite seeds (Prosopis pallida). European Food Research and Technology, 227, 1669-1676.

Correa, M. J., Salinas, M. V., Carbas, B., Ferrero, C., Brites, C., \& Puppo, M. C. (2017). Technological quality of dough and breads from commercial algarroba-wheat flour blends. Journal of Food Science and Technology, 54(7), 2104-2114.

Curti, E., Carini, E., Bonacini, G., Tribuzio, G., \& Vittadini, E. (2013). Effect of the addition of bran fractions on bread properties. Journal of Cereal Science, 57(3), 325-332.

Díaz-Batalla, L., Hernández-Uribe, J. P., Román-Gutiérrez, A. D., Cariño-Cortés, R., Castro-Rosas, J., \& Téllez Jurado, A. (2018). Chemical and nutritional characterization of raw and thermal-treated flours of mesquite (Prosopis laevigata) pods and their residual brans. CyTA-Journal of Food, 16(1), 444-451.

Felker, P., Grados, N., Cruz, G., \& Prokopiuk, D. (2003). Economic assessment of production of flour from Prosopis alba and Prosopis pallida pods for human food applications. Journal of Arid Environments, 53(4), 517-528.

Giaretta, D., Lima, V. A., \& Carpes, S. T. (2018). Improvement of fatty acid profile in breads supplemented with Kinako flour and chia seed. Innovative Food Science \& Emerging Technologies, 49, 211-214. https://doi.org/10.1016/j.ifset.2017.11.010.

Gonzales-Barron, U., Dijkshoorn, R., Maloncy, M., Finimundy, T., Calhelha, R. C., Pereira, C., ... Cadavez, C. (2020). Nutritive and bioactive properties of mesquite (Prosopis pallida) flour and its technological performance in breadmaking. Foods, 9(5), 597. https://doi.org/10.3390/foods9050597.

Gray, J. A., \& Bemiller, J. N. (2003). Bread staling: Molecular basis and control. Comprehensive Reviews in Food Science and Food Safety, 2(1), 1-21.

Machado-Alencar, N. M., Steel, C. J., Alvim, I. D., Morais, E. C., \& Andre-Bolini, H. M. (2015). Addition of quinoa and amaranth flour in gluten-free breads: Temporal profile and instrumental analysis. LWT - Food Science and Technology, 62(2), 1011-1018.

Marangoni, A., \& Alli, I. (1988). Composition and properties of seeds and pods of the tree legume Prosopis juliflora (DC). Journal of Science of Food and Agriculture, 44, 99-110.

Regulation (EC) No. 1924/2006 of the European Parliament and of the Council of 20 December 2006 on nutrition and health claims made on foods. Official Journal of the European Union OJ L12. :3-18. Corrigendum 18.1.2007.

Rinaldi, M., Paciulli, M., Caligiani, A., Scazzina, F., \& Chiavaro, E. (2017). Sourdough fermentation and chestnut flour in gluten-free bread: A shelf life evaluation. Food Chemistry, 144-152.

Schiraldi, A., \& Fessas, D. (2001). Mechanism of staling: An overview. In P. Chinachoti, \& Y. Vodovotz (Eds.). Bread Staling. Florida: CRC Press.

Sciammaro, L. Ferrero, C., \& Puppo, M. C. (2016). Chemical and nutritional properties of different fractions of Prosopis alba pods and seeds. Journal of Food Measurement and Characterization, 10(1), 103-112.

Zolfaghari, R., Harden, M., \& Huffman, L. (1986). Some physical and chemical properties of honey mesquite pod Prosopis glandulosa and applications in food products. Cereal Chemistry, 63(2), 104-108. 